\title{
BOURDIEUSIAN GAP: \\ RE-READING THE CONCEPT OF HABITUS \\ IN THE LIGHT OF THE THEORY OF CULTURE
}

\section{Paweł Winiarski*}

\section{Abstract}

The article shows the possibilities of using Pierre Bourdieu's theoretical achievements on the basis of Jeffrey C. Alexander's strong program in cultural sociology. The author tries to solve the problem of reductionism by reinterpreting the Bourdieu's key concepts in the spirit of Yuri Lotman's semiotic theory of culture. Lotman's understanding of culture, including the reproduction and creation, allows to explain not only how the structures affect the individuals, but also how individuals use the structures.

Keywords: habitus, strong program in cultural sociology, cultural memory, semiosphere

Creating the English-language version of the journal "Zoon Politikon" is financed under contract No. 724/P-DUN/2018 from the funds allocated by the Minister of Science and Higher Education for dissemination of science.

\footnotetext{
*Paweł Winiarski, M.A., Warsaw University, Poland, mail: p.winiarski3@uw.edu.pl ORCID: https://orcid.org/0000-0002-0228-3732
} 
Introduction

Theaim of the presented article is to build a bridge between the relational social model formulated by Pierre Bourdieu and the strong program of cultural sociology of J effrey C. Alexander. I start with a revision of the of Alexander and Smith's critical reflection regarding to the hermeneutic power of Bourdieu's research program. Authors indicate a gap in Bourdieu's concept that spreads between the habitus and its conditions. Next, I am interpreting the concept of habitus, referring to Wilhelm Dilthey's hermeneutics, structuralism of Ferdinand de Saussure and texts worked out inter alia during the linguistic turn (Paul Ricoeur, Yuri Lotman). It leads to the conclusion that the titled "gap" can be exceeded by using terms developed by Yurij Lotman such as: semiosphere, semiotic memory of culture, translation. The reinterpretation of the habitus in the Lotman's way of thinking can be an interesting solution that brings researchers benefits on both - hermeneutic and methodological - levels.

A strong point of Alexander's research program is the convincing presentation of culture as a generative principle, thanks to which the researcher has the possibility of an analytical transition between the micro and macro levels. An advantage of the Bourdieu concept is the relational model of social structure. Although Bourdieu defends the integrity of his concept (Bourdieu, Wacqouant 1992), it is worthy to try to reconcile both perspectives. To the end, it is necessary to make a shift in the Bourdieusian definition of conditions from materialistic-behavioral understanding (see: Alexander 1995, p. 131) towards a semiotic meaning. This movement implies a change in the meaning of habitus.

Alexander's Critique

In the essay The Strong Program of Cultural Sociology Alexander and Smith consider, among other things, which of the interesting from their 
point of view theoretical concepts meet the requirements of a strong program (Alexander et al. 2003). They treat Bourdieu's achievement as one of the weak programs, despite it has "real merits" (Ibidem, p. 18) According to the authors, Bourdieu does not explain in a satisfactory way the mechanism in which culture shapes the habitus. In their criticism, they state that, in the French sociologist's view, culture - as a strategic resource belonging to the external environment of action, where status groups compete in various fields - is a variable dependent on the specific conditions characteristic of the social class (independent variable). Hence, they argue that Bourdieu does not explain how the process of reproduction follows and what is the meaning of culture as a text shaping the world in which members of particular classes live. In the criticized view, culture "has a role in ensuring the reproduction of inequality rather than permitting innovation" and although "People use culture, but they do not seem to really care about it" (Ibidem). All this prompts Alexander and Smith to say that in the face of the missing link, Bourdieu's theory does not have, from the point of view of a strong program, a hermeneutic power to understand the processes of cultural activity.

Alexander's point of view is based on the change of perspective made by Talcott Parsons. It relies on not perceiving individuals as participating in a specific society that is outside of them. Parsons analytically weaves the individual and society, which allows us to look beyond the specific observed images. Alexander takes over from Parsons a model of three systems (personality, social and cultural) that was "to break down the concrete sense of the actor" (Alexander 1998, p. 211). Thanks to it, analytical access to interpenetration of the interpretation of subjectivity and objectivity, personality and society as well as culture and needs is possible. An attempt to synthetically analyze these classic dichotomies is theintention sharingby Alexander and Bourdieu. However, 
Alexander criticizes Bourdieu primarily for a reductionism (Alexander 1995).

The strong program intercepts from the neo-functionalism the models of action and order (Alexander 1988). At stake here is the formulation of a general model of the relationship between individual action and collective environments, and thus reconciliation on micro and macro perspectives. Alexander perceives action as a process that takes place in social, cultural and personality environments and is spread between the dimensions of interpretation, which is irrational, and strategy based on purposeful-rational designing of goals. As part of the social system, the processes of typification, invention and strategy are under the tension with intersecting roles and diversified expectations of which the full realization is not possible. Hence, playing role is an economic game of subordination and evasion, in which individuals strive to set the optimal trajectory for themselves (this point of the Alexander model is close to Bourdieu's field theory). Alexander accepts the analytical concept of personality and society to root action in proximate actors and agencies (Alexander et al. 2003, p. 14). In the Alexander model, the concept of agency is an important and problematic one. "Actors per se are much more, and much less than »agents«" (Alexander 1998, p. 215).

Agility is defined here as the moment of freedom that occurs within the systems internally located with respect to the actor. This model has, as I havealready pointed out, an analytical and not a concrete character. Meanwhile, according to Alexander, Bourdieu gives personality and society a specific form. In the end this leads him to separate what should not be separated from Alexander's perspective. In the Bourdieu model, the society is reduced to the influence of power networks exerting a decisive influence, which have an economic dimension (in the widest meaning of the term). This is Alexander's main objection to the concept of field (1995). 
The society defined by Bourdieu influences the actors from outside. As a result, the concept of habitus captures the problem of subjectivity in a deterministic and anti-voluntaristic form (Alexander 1995, p. 131). In this approach, the culture of economization becomes a limitation rather than the space of creative activity. It reproduces the structure of domination rather than enables a change.

Bourdieu's Program: Close and Distance

Bourdieu's research program is, in principle, culturalistic. Bourdieu attempts to break the social dichotomy. In particular, it aims to exceed the limitations that result from the division into perspectives with objective and subjectivist attitudes. For this purpose, it adopts the category of rationality as the one by which it is possible to determine a common analytical plane for processes from different levels (cultural, social and economic). Trying to operationalize the social play of values, he postulates to exceed the economic reductionism. According to Bourdieu to narrow the understanding of the concept of capital to the sphere of economy makes impossible to explain the social world and its structure.

This is because many non-economic relationships seem irrational if we do not take into account other stakes that can be activated in social relations or in the cultural field. This idea directs the reader towards a broad culturalistic interpretation in which capital is a metaphor of the causative power, such as is culture. The widely understood capital embodies the power of various cultural resources. Bourdieu argues that the analysis of capitalist society requires thinking about it in the basic categories it generates and imposes, in terms of interest, profit, capital and its accumulation (Bourdieu 1986).

In order for a such analysis, Bourdieu postulates to overcome the reduction that the economy makes, narrowing the meaning of the concept of capital only to an exchange based on the value that embodies money, 
omitting other cultural and social forms of profit. The metaphor of capital, which Bourdieu uses when he developed the concept of Marx, discloses culture as a kind of power that drives man's production of reality. Different dimensions of culture, various channels of its transmission, various resources owned by individuals, Bourdieu illustrates in the concept of capitals, indicating precisely the aspect of force or forces that become the essence of human action. The broad definition of capital allows to understand social games using the categories of rationality.

The Bourdieu movement, which proposes this socially expressed power of culture to operate in the form of economic, social and cultural capital, is to some extent comparable to Alexander's operation, which distinguishes the environments of action: cultural, social and personality. This is about operationalizing the heterogeneity of structures / environments that affect on action. Bourdieu, focusing on the socio-structural aspect, is primarily interested in the real networks exchanging various types of values. In a formulating the concept of habitus, Bourdieu proposes a way of understanding the process in which objectified culture is embodied in the dispositions of the body and mind. It is a movement between objectified and embodied capital. At the same time, due to the embodied capital, players can use objectified capital. The provider of cultural resources that can be embodied is the social class.

Bourdieu shows a dynamic and heterogeneous picture of a living society through the competition of capitalized cultural dispositions. Individuals strive to occupy beneficial positions in the social structure, thanks to the value that they have in their context (field) their competences, material resources and interpersonal contacts. From Alexander's point of view, the concept of Bourdieu's capital is burdened with the assumption of the rational nature of action. This is where the charge of reductionism appears. Alexander recognizes acting as both rational (strategizing) and irrational (interpretation). Both of these aspects can 
be operationalized within the framework of the semiotic concept of Lotman, and the dynamics of the field can be studied as a movement within the semiosphere.

Bourdieu shares with Alexander the belief in the autonomy of culture (1986, p. 50). However, the difference that Alexander makes the basis for his criticism lies in the internal placement of culture as the driving force, and thus the difference in the vector of its operation. While Alexander emphasizes that the environments that shape human action are located within the actors and that their action goes towards externalization (1988), Bourdieu places them outside in the form of objective conditions. The action vector is directed to the interior of the individual. Habitus is "external wealth changed into an integral part of the person" (1986, p. 48). The social structure is understood here as an objective network of relations between positions whose conditions are imposed on subjects (Bourdieu, Wacqouant 1992).

Bourdieu illustrates culture as objectified and accumulated work. Such definition shows that, as for Alexander, one of the central problems of his theory is an action. In Bourdieu, the subjects action relies on the one hand, in appropriating culture and, on the other, in attempts to influence the distribution of objectively available resources. Social dynamics is driven by competition between subjects in the game, both for the resources themselves, the rules for their distribution, and for the profits of it.

Bourdieu inherits after Marx the concept of action understanding as work. At the same time, while for Marx the work was the embodiment of man's disposition for a creative and conscious transformation of the world (Marx 2007), this aspect in the case of Bourdieu is unclear. Bourdieu defines a social game not in terms of the creative contribution that entities make to it, but in categories independent of the will and consciousness of individuals inequality and power. Being an heir of Marx's critical sociology he seems to omit the essential ontological and ethical 
element of his (irrational by his selflessness) assumption about the creative essence of man.

The sociology of Bourdieu explains how the social distribution of culture and symbolic power takes place, and how the processes of reproduction of the social structure follow (Bourdieu, Passeron 1990). It does not explain, however, what are the sources of cultural change. The assertion that culture, although having autonomy and rights exceeding the will of subjects (Bourdieu 1986, p. 50), is historically man-made and works due to embodiment, is not a satisfactory solution to the problem of action. Bourdieu focuses his attention on the structural and social dimension. He explains how entities use culture in the social game, activating their dispositions and trying to get a satisfactory return in the form of a certain range of power. From Alexander's point of view, this is focusing on the problem of strategization - hence, the accusation of reductionism.

The goal of both, Alexander and Bourdieu, is to find the generative principle. Both are trying to transcend the imposition of impersonal structures over action imposed by structuralism. In Bourdieu concept, the rule that allows us to understand practices, judgments and the configuration of capitals is the principle of habitus (Bourdieu 1984, p. 170). Habitus "is both the generative principle of objectively classifiablejudgments and the system of classification (principium divisionis) of the practises" (Ibidem). Bourdieu says: "This means that inevitably inscribed within the dispositions of the habitus is the whole structure of the system of conditions, as it presents itself in the experience of a lifeconditions occupying a particular position within that structure" (Ibidem, p. 172). Then, he refers to the binary oppositions described by Mauss and Durkheim (1963). Here - in the relationship between conditions and the habitus - there is, I believe, a gap that disturbs American sociologists. 
From the point of view of the strong program a notion of habitus shows the socially mediated attribution of various aspects of life. Society depicted as a complex network of internally diverse social classes acts as a generator of structurality. It creates objective conditions. At the same time Bourdieu's concept of objectivity is not so much ontological as analytical and methodological. The point is that society can be studied as an objective structure that puts pressure on individuals (Bourdieu 1984). This does not mean, however, that this influence is fully deterministic. Bourdieu's social structure acts as a language (langue). Habitus is a class defined set of internalized structures that allows to adjust the action to the requirements created by the social class and the field within the game is being played on the one hand and on the other one to owned capitals and aims.

According to Alexander, the generative principle should be associated with culture as the most autonomous operating environment. And since the habitus does not refer directly to culture as a meaningful system, it cannot explain the generative mechanism that conditions it. In order to operationalize the doubts of Alexander and Smith, one should ask: how is this experience inscribed in the habitus structure? What cultural mechanism is behind this process? If the basic structural oppositions, such as up / down, near/ far impose - as Bourdieu writes - as the most fundamental principles of structuring practices and judging of these practices and the habitus is a system of generating them, one should ask what is the essence of these oppositions? This essence is based on assigning value and, hence, giving meaning. This is how the relationality of a structure is realized, whose binary oppositions are the beginning or which they represent. It seems, therefore, that between experienceand the habitus there is an irrational process of giving meaning, which Alexander describes with the concepts of typing and invention (Alexander 1988). 
The conditions available in culturally mediated experiences always create a present and unconsciously interacting relationship that structures the reception of reality as a whole (Dilthey 2010). At this point, the problem could be considered as closed, if not for the question raised by Paul Ricoeur's reflection on loneliness (Ricoeur 1976, p. 19). Habitus, to be a principle that generates practice must be objectified that is, be a feature of groups, social worlds, not just individuals.

As has already been shown in the quoted passage from Distinction, according to Bourdieu habitus arises in response to the structure of the conditions in which the individuals are located (Bourdieu 1984). Bourdieu develops here the Marxian conception of the relationship between being and consciousness. However when you look at this relationship from the point of view of Dilthey's philosophy, the life-experience relationship consisting of the sequence: emotional reaction, evaluation and language-mediated design of action will be found in the place of the Bourdieusian conditions-habitus relationship.

The conclusion that follows is this: if we want to recognize habitus as a deep generative principle, as a bundle of dispositions structuring practices and their evaluation, it means that the basic activity that the habitus expresses is not a behavioral reaction to being, but action based on objectified assessment of experience, which is done by assigning meaning. In this approach, the habitus would refer to the broadly understood cultural competences of the individual, shaped in the course of social relations in accordance with the principle of memory - i.e. expressed in action (including communication) to maintain or forget the elements of culture relevant to a given group. Bourdieu's interpretation makes it possible to approach semiotics as an analytical tool in the humanities and overcome the problem of the gap that Smith and Alexander have pointed out. 
In a Search of a Common Generative Principle

The purpose of this article is not to make a decision for one of the giants of sociology, but to try to climb onto their shoulders. Breaking the deadlock, between the unquestionable advantages of Bourdieu's theory and its criticism by Alexander, may rely on adopting the interpretation line, according to which the operation of the habitus basically consists in the schematizing and structuring work of culture not the social class. The culture which in the form of semiotic remembrance and semiosphere is associated with texts specific to particular social worlds, including: grammars, axio-normative systems, classifications, rituals, gestures, artifacts, programs and strategies of action, as well as the Bourdieusian sense of taste and based on the mentioned elements of the practice that can be treated as some kind of competence in creating / reproducing and reading cultural texts. It is the specificity of culture as characteristic memories transmitted from generation to generation, significant experiences of a given social world that has the power Bourdieu writes about, and makes it so difficult for an individual to break out of the frame of objectified reality - and if it does, then only it is to fall into the embrace of another alternative system.

The aforementioned considerations guide us to the non-traditional concept of memory. In the classic approach, which has its source in Halbwachs' works (1992), memory is a psycho-social phenomenon that can be studied and, through this, draw a picture of the specificity of social groups, their diversity and relationships. The social positioning of the individual creates a symbolic framework that defines its memory. Memory here is a variable dependent on practices resulting from a socio-structural position. The resulting research approach should - from Alexander's perspective - be included into the weak programs. 
However, in the approach proposed here, memory is a mechanism of cultural diachrony (ensures continuity and relative stability of the social structure), and in the synchronous perspective - an important resource in the socio-structural game (in this way we can look at the essence of various sub-cultural capitals). We can therefore talk about it not only as a phenomenon, but also as a research method, thanks to which we gain an insight into the culture in statu nascendi, expressed in various practices.

These practices, regardless of whether they have a linguistic character, or their communicative aspect is hidden, are significant systems. Inhabitants of social worlds, weaving networks of everyday practices, say something to themselves, to each other, and to the inhabitants of other surrounding worlds. What makes these worlds stable over time? That it is so difficult to migrate between them? That the price of effective migration is the need to undergo acculturation?

Bourdieu would say - habitus, but from the point of view of the strong program we will say - culture in its three-facetted essence, which consists of: language - as a mechanism for objectification of experiences, memory - as a mechanism for transmitting meanings and the semiosphere encompassing it - as a semiotically conceptualized culture (Lotman 1990). In a weak program, memory is a variable depending on the conditions that created it (see Halbwachs 1992). In the strong program, memory is a culture itself, an independent variable that both allows the consolidation of objectivity of individual experiences, and provides reference points in the programming of future experiences of members of a given community (Lotman, Uspensky 1978). It is here that we find a parallel with the Bourdieusian habitus. Memory as a cultural mechanism stabilizes the social structure. When Bourdieu notices that the habitus may change, but it is much more likely to become fixed, one can ask the Alexander's question: but how is this happening? 
On Bourdieu's ground, the answer would be as follow: conditions are or are not fundamentally changed, as a result of which either the acculturation happens or not. However, from the point of view of the strong program, this is an insufficient answer, disclosing the titled "gap". Only the view from the perspective based on the hermeneutic ground of the semiotic theory of culture makes it possible to understand the mechanism of reproduction. From the point of view of a strong program, the question of what actually is a habitus requires a Dilthey's view of "inner meaning" (Alexander et al. 2003, p. 13). This leads to questions: what is culture, how it exists and how it works, how it is subject to change, how it lasts, and finally - how does it affect individuals and communities?

Towards a Cultural Interpretation

Hence, how can we study the world extended between its individual, imaginary existence in unit selves, and its cultural and social dimension, which these images structured and make them become a reality felt together? De Saussure's conception of the sign combining a concept and an acoustic image assumes that the concept is an unambiguous, closed and containing the truth about the thing it concerns (de Saussure 1983). In this approach, the concept is a mirror of reality. From another point of view, the concept, understood as a metaphor of reality, compares incomparable things with one another, establishing a semantic relation between the external reality and its understanding by the subject. The metaphor, which is based on similarity and not identity, shows the tension between reality and its perception, also contains a surplus of sense which appears when the sign becomes an element of discourse (see Ricoeur 1976).

The meaning of the sign is not unambiguous and does not refer to the immanent truth about things. The meaning of the sign, and hence 
the semantic content of the concept, each time will define the discourse (including the letter or other iconic or significant element of culture). This means that the truth about the thing to which the notion of the concept prescribes the right is not a feature of the concept or thing, but the relation of the subject to the thing (Znaniecki 1968, Rorty 1989). This interpretation means that the concept is a heterogeneous being that reveals various meanings depending on who, when and for what purpose it is used.

The use of metaphor is not a kind of substitution. The concept does not replace things. The thing represents itself and has no meaning (and in any case it is unknown until the thing becomes the object of someone's experience). Concept as a metaphor "tells us something new about reality" (Ricoeur 1976, p. 53), it is a creation of a new one - an innovation - allowing for the appearance of a model of things within the semiosphere. The concept is an act of translation (Lotman), or understanding (Dilthey). It transforms what is external into the element of life. This creative act lies at the foundation of culture and is the generator of all diversity within it, which, through its distinctive character, translates into a social structure. Looking in this way, concepts are symbols, that is, "they point out beyond themselves to something wholly other which manifests itself in them" (Ibidem, p. 53). Dual character of the symbol - linguistic and non-linguistic - indicates its function in culture, which is the fixation in the language of non-linguistic phenomena.

Every use of language (I accept here a broad definition in which all significant and communicative activities are located) has a dual power. On the one hand, the individual is subject to the structuring power of culture and reproduces the symbolic network of meanings in which he is suspended (Geertz 1973, p. 5). On the other hand, with the help of a tool such as culture, he/ she makes a creative act of translation (Lotman) of his/ her individual experience into a form in which he/ she can 
communicate it to itself and others. Language is "a process by which private experience is made public" (Ricoeur 1976, p. 19).

Therefore, every use of culture, although it runs within the semiosphere, is to some extent unpredictable and can have consequences for the whole system. Language, when it becomes speech (de Saussure 1983), is not symmetrical. It is entangled in biography and history. Intersubjectivity (Schütz 1967) is based on a continuous process of reconciling meanings - on the precision and contextualization of metaphors. Lotman calls this phenomenon a translation and says that it is by definition a creative act, i.e. focused on producing new meanings. That is why language and culture are constantly changing - they are alive.

It does not change the fact that the phenomena of reality areincluded in patterns - that is, they are objectified and structured in the form of a "coherent world" (Berger, Luckmann 1991, p. 33). The order of reality is continually reproduced by the language that structurally organizes the world (Ibidem, p. 36; Lotman, Uspensky 1978, p. 212 213). In this way, the culturally generated reality is organized in the form of semantic fields (Berger, Luckmann 1991, p. 56) or sub-semiospheres (Lotman 1990, pp. 123-281), which have a diverse range (they may include the specificity of a certain profession, field of knowledge or cultural space). The subsequent stages of socialization that progress through life allow individuals to internalize knowledge (Berger, Luckmann 1991) or memory (Lotman, Uspensky 1978) and participate in the process of cultural transmission in this way.

At the same time, the specificity of knowledge / memory of individual social worlds means that reality is not homogeneous. "Participation in the social stock of knowledge thus permits the »location « of individuals in society and the »handling " of them in the appropriate manner" (Berger, Luckmann 1991, p. 78). This orientation is facilitated by a system of signs and symbols as well as myths (Barthes 1991) thanks to which individuals create, recognize, transmit and validate typifications, 
objectivities, roles, institutions. In a nutshell, they are able to use the texts of culture that creates their living environment and exerts the full power of institutional order that is "brought to bear with more or less equal weight on each individual, producing a compelling massivity for the objective reality to be internalized. Identity then is highly profiled in the sense of representing fully the objective reality within it is located" - summarized the authors of The Social Construction of Reality (Berger, Luckmann 1991, p. 184).

Here are the Bourdieusian "conditions" - shown in the cultural perspective as a culturally conditioned "being" in a dialectical coupling with un/ consciousness. The shaping of personality is achieved by subjecting the individual to the rigors of social institutions (Ibidem, p. 72), among whom the process of its socialization takes place. Articulating this idea in the language of semiotics of culture, it means that in the communication process a linguistic model of a certain fragment of the space of human cooperation (typification) was created, and then this model was fixed in the memory of culture (institutionalization). This process takes place in the course of a common history (Ibidem), and thus includes the element of sub-culture of a given social world - the cultural tradition of this world, which Yurij Lotman calls the semiotic memory of culture (Lotman, Uspensky 1978; Lotman 1990) and Berger with Luckman calls: "habitualized action" (Bereger Luckman 1991, pp. 70-71). The widespread availability of meanings and language models in a given community results in the imposition of patterns of behavior that are shaped in the course of socialization.

The habitus is also shaped by the conditions that the socialization environment creates. It's just that the generative mechanism of this process is not in the social environment (Bourdieusian social class) but in the cultural environment. The basic tool of socialization is language, with its help the inner structure of the semiosphere of the social world is communicated and internalized with its canonical domain, taboos, 
norms, values, motivations and institutions. Habitus is shaped in a network of metaphors that define the individual, expectations of its actions, choices, and judgments.

In order to be able to use the concept of habitus and the field theory on the basis of a strong program, it is necessary to substitute culture for the concept of "conditions". However, a culture understood not as something external, objective and decisive, but as a relative autonomous, internal environment of action. An environment that exerts significant, through its autonomy, but not the only impact on action. Moreover, the environment which, through the semiotic mechanism of its functioning, is based on irrational factors of interpretation (according to Alexander) and translation (according to Lotman) and as such cannot be reduced to the economy of practices. This means that the habitus, which is activated in the social game in the form of various capital, should be understood as a specific, generalized cultural resource of the individual or the social world. On the other hand, the social field, showing the structure of relations between the units in motion (trajectory), conceals a deeper cultural layer, which is the semiosphere organization. In other words, the social reconstruction of the semiosphere structure by assigning values and norms to specific individuals or groups is just a field. The social structure reproduces not an objective external world, but cultural imaginaries about it - wrote Durkheim and Mauss (1963).

Theoretical Conclusion

To reconcile Bourdieu's theoretical concept with the strong program, we should reverse the dependencies. Culture cannot be treated only as a resource depending on the class position, because it is, at the same time, according to Alexander, the most autonomous environment of action. Therefore, the social class should be treated as an expression of 
the specificity of culture (sub-semiosphere). Habitus expresses everything that has been internalized by the individual. The conditions that create it are the symbolic universe in which individuals live. The concrete form of habitus reflects the cultural dominant of a given social world.

A special place in this process is occupied by constellations of meanings internalized in the process of primary socialization. They are the deepest internalized and the most "transparent" - that is, they appear to the individual as a kind of objective canon structuring the reception of reality and offering the most durable axio-normative and motivational system, allowing to choose such and no other patterns of actions. This process can be explained at the generative level, referring to the concepts of the semiosphere and the semiotic memory of culture. This allows to transfer Bourdieu's external environments of action, which are culture and society, inside the actor.

The term semiosphere is analogous to the concept of the biosphere from which it derives its etymology. Semiosphere is the cultural environment of human life - the habitat. Memory, as its aspect, is a factor that ensures continuity and structure of social worlds by identifying the meaning of any linguistic and otherwise meaningful metaphors. The semiotical memory of culture is the key to reading cultural texts. Each social world through its specific cultural tradition (semiotic memory of culture) has its own key or pattern. Memory, as a historically shaped constellation of meanings, communicated and defined by language, structures both the dispositions of individuals and their perception of the cultural and social universe. In this perspective, it is the transmission of semiotic memory that sets individuals in the subcultures of social worlds - habitats. Thus, it has a memory of a habitative role - it is a Bourdieu's habitus shown from the mechanism of action, for which Bourdieu, according to Alexander and Smith, does not give a satisfactory justification. 
Methodological Conclusion

If we assume that the semiotic remembrance of culture is the aspect that makes continuity of culture possible, it means that the cultural and social processes can be read from the actions of individuals. These activities communicate meanings specific to the subcultures of social worlds. In this way, the captured memory of culture becomes a methodological term. It means that all narratives, institutions, practices and relations function in the dialectical relationship of structuring within the semiosphere (they constantly reproduce and modify it). All of them can be empirically registered as surface phenomena of culture, allowing simultaneously insight into the processes occurring in its deeper layers. The specificity of language usage characteristic of social worlds, historically shaped understanding of language metaphors, ways of reconstructing the past and designing the future are included in a definition of the semiotic memory of culture. A researcher who works with the qualitative method, deals with the narrative of his interlocutor, which have character of the memory's sentences or projections. In both cases, as was shown by Lotman and Uspensky (1978), the researcher registers the content of the semiotic memory of culture. Projection of the future is just one of its vectors. For this purpose when we are designing the future, we do not know what will become its content. There are no signs that can express what is unknown in the future. The only tool we have, wanting to construct the future, is the objectified past experience - the memory.

Similarly, at the theoretical level, Alexander describes this mechanism, by formulating the concepts of interpretation, typing and strategy (1988). Hence, the recording of narrative during the fieldwork (regardless of whether the examined is oriented in the forward or backward of the time continuum), gives an insight into the content of cultural 
memory, internalized by the interlocutor as a representative of the social world / worlds that shaped him. The memory understood in this way is a term enabling research on one semiotic level of resources and disposition resulting from the experience of individuals and cultural traditions of different communities, as well as relations between them that take place and find a structural and social image.

Lotman's concept of semiotic remembrance of culture, both on a generative and methodological level, enables the theory of culture to clarify what is and how the habitus arises. Built in this way, the theoretical bridge allows to fill the gap in the Bourdieu theory indicated by Alexander and Smith. The question is, however, whether this reinterpretation does not fill the Bourdieusian metaphors with a new, alien content? What is the purpose of this procedure? One can easily combine Alexander's sociological theory with the methodological guidelines of Lotman, without bothering Bourdieu. Exceeding the Bourdieusian gap, however, allows, in my opinion, to free the economics of practices and the field theory from economic reductionism (Alexander 1995). At the expense of rejection of the materialistic base and a thorough reinterpretation of the concept of action, a researcher wishing to pursue a strong program of cultural sociology can use the model of social fields.

\section{References}

Alexander J.C. (1995), Fin de Siècle Social Theory. Relativism, Reduction and the Problem of Reason, Verso, London- New York

Alexander J .C. (1988), Action and Its Environments, (in:) Action and Its Environments, Toward a New Synthesis, (Ed.) Alexander J ., Columbia University Press, New York 
Alexander J .C., (1998), After Neofunctionalism: Action, Culture, and Civil Society, (in:) Idem, Neofunctionalism and After, Blackwell Publishers Ltd, Malden- Oxford

Alexander J.C., Smith P. (2003), The Strong Program in Cultural Sociology: Elements of a Structural Hermeneutics, (in:) The Meanings of Social Life: A Cultural Sociology, Oxford University Pres, Oxford

Barthes R. (1991), Myth Today, (in:) Idem, Mythologies, The Noonday Press, New York

Berger P.L., Luckman T. (1991), The Social Construction of Reality. A Treatise in The Sociology of Knowledge, Penguin Books, London

Bourdieu P. (1984), Distinction. A Social Critique of the Judgment of Taste, Harvard University Pres, Cambridge, Massachusetts

Bourdieu P. (1986), The forms of capital, (in:) Handbook of Theory and Research for the Sociology of Education, (Eds.) J. Richardson, Greenwood, Nowy York.

Bourdieu P., Wacqouant L.J.D. (1992), An Invitation to Reflexive Sociology, Polity Press, Cambridge

Bourdieu P., Passeron J .-C. (1990), Reproduction in Education, Society and Culture, Sage Publications, London- New Delhi

Dilthey W. (2010), The Formation of the Historical World in the Human Sciences, (in:) idem, Selected Works, Volume III, Princeton University Press, Princeton

Durkheim E., Mauss M. (1963), Primitive classification, Cohen and West, London

Geertz C. (1973), The interpretation of cultures: selected essays, Basic Books, New York

Halbwachs M. (1992), On collective memory, The University of Chicago Press, Chicago

Lotman Yu.M., Uspensky B.A. (1978), On the Semiotic Mechanism of Culture, "New Litereary History" Vol. 9, No. 2 
Lotman J . (1990), Universe of the Mind: Semiotic Theory of Culture, I.B. Tauris \& Co. Ltd. Publishers, London- New York

Lotman J . (2009), Culture and Explosion, Mouton de Gruyter, Berlin- New York

Marx K., (2007), Economic and Philosophic Manuscripts of 1844, Dover Publications, Mineola

Ricoeur P. (1976), Interpretation Theory: Discourse and the Sulplus of Culture, The Texas Christian University Press, Texas

Rorty R. (1989), Contingency, irony, and solidarity, Cambridge University Press, Cambridge

Saussure F. de (1983), Course in General Linguistics, Open Court. La Salle

Schütz A. (1967), Phenomenology of the Social World, Northwestern University Press, Evanston

Znaniecki F. (1968), The method of sociology, Octagon Books, London 